\title{
Case report of a primary prostatic urothelial carcinoma patient with sustained fever
}

This article was published in the following Dove Press journal: OncoTargets and Therapy

\section{Songsong Zhang \\ Zhenxing Guo}

Department of Hematology/Oncology, Cancer Center, First Hospital of Tsinghua University, Beijing, 100016 , People's Republic of China
Correspondence: Zhenxing Guo Department of Hematology/Oncology, Cancer Center, First Hospital of Tsinghua University, Beijing, 100016, People's Republic of China

Tel +86 I064308530

Email gzx2962@outlook.com

\begin{abstract}
A 77-year-old-male patient presented with recurrent gross hematuria for 3 months with a fever for 1 month, and so was admitted to The First Hospital of Tsinghua University. The medical history revealed the patient exhibited no symptoms of night sweat, dysuria, or abdominal pain. The patient experienced sustained fever with maximal temperature of $39^{\circ} \mathrm{C}$ for 1 month without any infectious symptoms. The biochemical examination revealed that renal and hepatic function tests were normal. Serum prostate-specific antigen and free prostate-specific antigen were at a normal level. Enhanced computed tomography and magnetic resonance imaging was performed and indicated prostatic cancer with bilateral pulmonary metastases. Subsequently, prostatic urothelial carcinoma was confirmed by a histopathology assay of the prostate biopsy. Following 1 course of chemotherapy, the temperature of the patient returned to normal.
\end{abstract}

Keywords: prostatic urothelial carcinoma, primary, fever, chemotherapy, metastases

\section{Introduction}

The prostate gland consists of glandular elements and fibromuscular stroma. Prostatic urothelial carcinoma (PUC) may originate from the mucosa of prostatic transitional urothelium, prostatic ducts, or prostatic stroma. The incidence of primary PUC is extremely rare and accounts for only $1 \%-4 \%$ of prostatic malignant tumors. ${ }^{1}$

In the present study, we report a case of a 77-year-old-male, who was admitted to the Department of Hematology/Oncology, The First Hospital of Tsinghua University (Beijing, People's Republic of China) with a history of recurrent visible hematuria for 3 months with fever for 1 month. Subsequently, the patient was diagnosed with primary PUC. Following 1 course of chemotherapy, his temperature returned to normal.

\section{Case report}

A 77-year-old-male was admitted to our hospital with a history of recurrent visible hematuria for 3 months and fever for 1 month on February 4, 2017. Medical history showed he had no symptoms of night sweat, dysuria, or abdominal pain. He experienced sustained fever with maximal temperature of $39^{\circ} \mathrm{C}$ for 1 month without any infectious symptoms. Prostate cancer was highly suspected after palpation of the prostate. Biochemical examination showed that renal and hepatic function tests were normal. Serum prostate-specific antigen (PSA) and free PSA were normal. Subsequent pulmonary enhanced computed tomography (CT) scan showed multiple metastatic tumors in both lungs (Figure 1). Moreover, an enhanced magnetic resonance imaging (MRI) of the prostate was performed and revealed the prostate was enlarged in size $(4.2 \times 4.7 \times 6.2 \mathrm{~cm})$ with multiple high signals indicating small nodules in the diffusionweighted imaging image. Also, multiple enlarged lymph nodes in the pelvic cavity were 

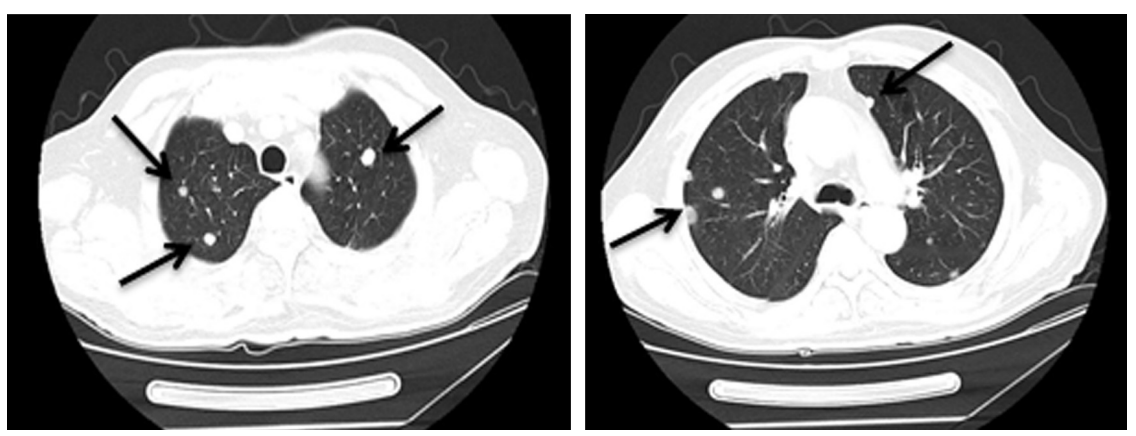

Figure I Contrast-enhanced CT of pulmonary revealed bilateral pulmonary metastases (arrow). Abbreviation: $\mathrm{CT}$, computed tomography.

found (Figure 2). Pelvic cavity-enhanced CT scan showed the bladder was well filled with a uniform wall, no abnormal density foci, and macroscopic lesions. Then, prostate needle biopsy was performed by transrectal ultrasonography. Postoperative histopathology revealed poorly differentiated transitional cell carcinoma. Immunohistochemical staining showed the tumor cells were positive for cytokeratin (CK) 20(+), CK7(+), CK8/18(+++), CK5/6(+++), 34ßE12(+++), and P504S(+), but negative for CK34, D2-40, uroplakin, and PSA (Figure 3). Therefore, he was diagnosed as having primary prostatic poorly differentiated urothelial carcinoma. Finally, he underwent a chemotherapy regimen consisting of gemcitabine 1,200 mg d1, d8; cis-platinum $40 \mathrm{mg}$ d2-3 q3W. Following 1 course of chemotherapy, normal temperature was achieved by the patient.

\section{Discussion}

Primary PUC has an extremely low incidence rate. Melicow and Hollowell ${ }^{2}$ first reported carcinoma in situ of the prostate coexistent with bladder transitional cell carcinoma as Bowen's disease in 1952. Since then, several studies have reported transitional cell cancer involvement of the prostate with an incidence between $12 \%$ and $48 \%{ }^{3}$ However, the incidence of primary PUC is rare, and it usually occurs in elderly patients and is accompanied by hematuria or dysuria. The underdiagnosis of PUC is common, and most patients are at an advanced stage with distant metastasis at diagnosis. PSA is a highly specific biomarker for the prostatic lineage and almost exclusively synthesized in the prostate ductal and acinar epithelium. It has been confirmed that PSA level measurement plays an important role in the differential diagnosis of bladder cancer from prostate cancer. ${ }^{4}$ However, PSA is also expressed in some nonprostatic tissues and extraprostatic neoplasms, such as urethral, periurethral, perianal glands, cloacogenic carcinoma, salivary duct carcinoma, salivary gland pleomorphic adenoma, and rare breast carcinomas. ${ }^{5}$ Previous studies also suggested PSA staining intensity was negatively correlated with Gleason score, and it was also shown that patients with high-grade (Gleason score 8-10) prostate cancer might have low or even normal PSA level. ${ }^{6}$ Given the limitations of PSA, the clinical differential diagnosis becomes more difficult. Consistent with previous primary PUC results, ${ }^{7}$ the patient in our study had a normal serum PSA level, which suggested PSA level might be a useful
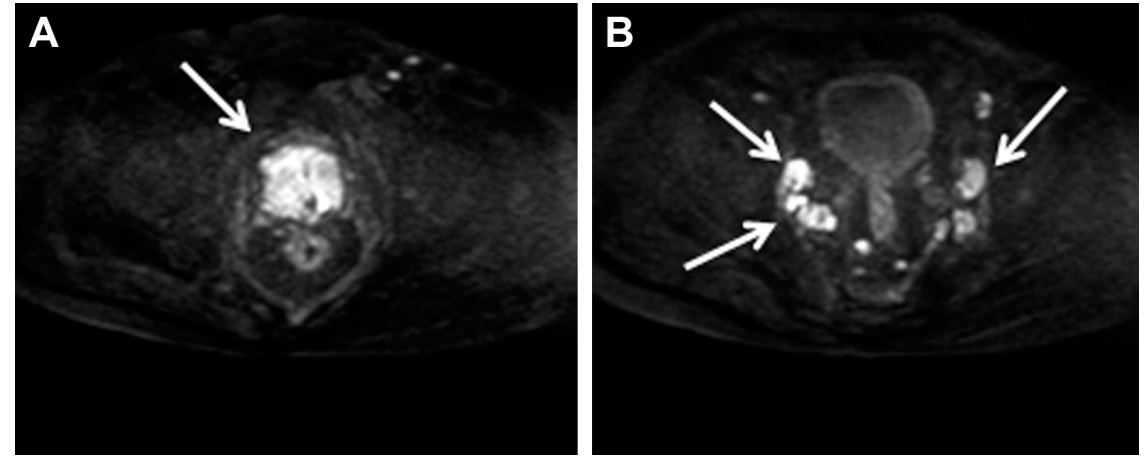

Figure 2 Enhanced MRI of prostate.

Notes: (A) Prostate was enlarged in size $(4.2 \times 4.7 \times 6.2 \mathrm{~cm})$ with multiple high signals of small nodules (arrow). (B) Multiple enlarged lymph nodes in pelvic cavity (arrow). Abbreviation: MRI, magnetic resonance imaging. 


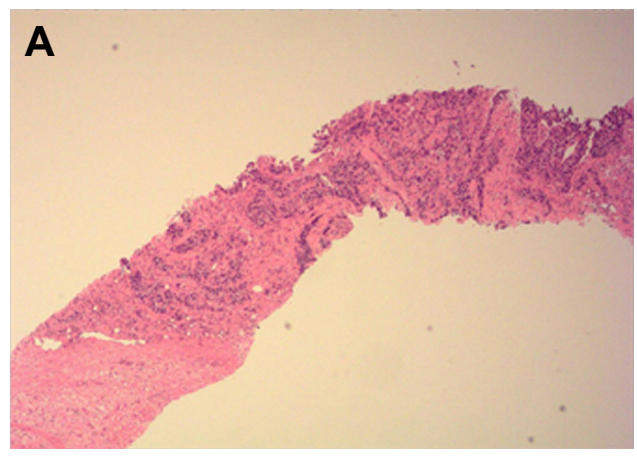

$40 x$

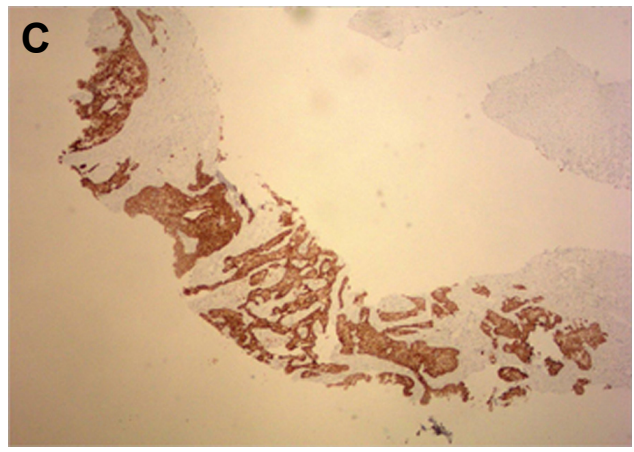

P504S
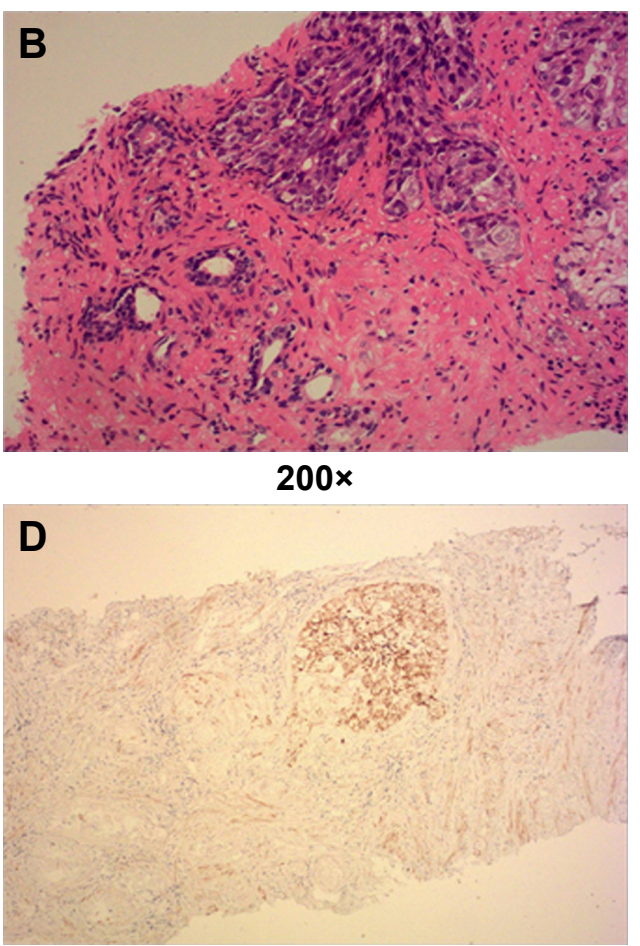

$34 \beta E 12$

Figure 3 Histopathology of prostate biopsy.

Notes: Postoperative histopathology of prostate revealed poorly differentiated transitional cell carcinoma (A) (H\&E, 40X) and (B) (H\&E, 200X). Histochemical staining of tumor cells for (C) P504S(+) and (D) 34ßEI2(+++).

Abbreviation: H\&E, hematoxylin and eosin.

biomarker to differentiate primary PUC from typical adenocarcinoma of prostate. Cystoscopy is described as a valuable tool to diagnose urothelial tumor if there are macroscopic lesions. In our study, we highly suspected prostate cancer after prostate palpation. Because pelvic cavity-enhanced $\mathrm{CT}$ and MRI scan excluded bladder macroscopic lesions, we did not choose further cystoscopy. Postoperative histopathology of prostate needle biopsy provided important evidence to support the diagnosis of primary PUC.

Liedberg et $\mathrm{al}^{8}$ showed primary PUC had a unique and separate staging system, which was different from prostatic adenocarcinoma. Radical surgery should be pursued for patients with PUC who are in the early stage of disease. For advanced-stage PUC, gemcitabine combined with cisplatinum is the first-line chemotherapy regimen. ${ }^{9}$ Cheville et $\mathrm{al}^{10}$ reported primary PUC with a poor prognosis and 5 -year survival rate of $52 \%$. Ichihara et al's ${ }^{11}$ study suggested that primary PUC patients with stromal invasion or lymph node metastasis have worse prognosis. Also, PUC patients with contiguous malignant involvement had a $7 \%$-year survival rate. ${ }^{12}$ The patient in our study had a much worse prognosis factor, ie, bilateral pulmonary metastases. Although gemcitabine combined with cis-platinum regimen achieved response, further follow-up is required to observe the long-term efficiency.

\section{Conclusion}

Primary PUC is a rare malignant tumor that involves the urinary system and is associated with a poor prognosis. Given the extremely low incidence of prostatic malignant tumors, further studies are needed to enlarge the number of cases and perform a multicenter, prospective cohort study to investigate clinical outcomes of primary PUC.

\section{Consent}

Written informed consent was obtained from the patient for publication of this case report and the accompanying images published.

\section{Acknowledgment}

This work was supported in part by grants of National Natural Science Foundation of China (81000228).

\section{Disclosure}

The authors report no conflicts of interest in this work. 


\section{References}

1. Shen SS, Lerner SP, Muezzinoglu B, Truong LD, Amiel G, Wheeler TM. Prostatic involvement by transitional cell carcinoma in patients with bladder cancer and its prognostic significance. Hum Pathol. 2006;37(6): 726-734.

2. Melicow MM, Hollowell JW. Intra-urothelial cancer: carcinoma in situ, Bowen's disease of the urinary system: discussion of thirty cases. J Urol. 1952;68(4):763-772.

3. Walsh DL, Chang SS. Dilemmas in the treatment of urothelial cancers of the prostate. Urol Oncol. 2009;27(4):352-357.

4. Dabbs DJ. Diagnostic Imunohistochemistry. 3rd ed. Philadelphia: Saunders-Elsevier; 2010:621-625.

5. Kamoshida S, Tsutsumi Y. Extraprostatic localization of prostatic acid phosphatase and prostate-specific antigen: distribution in cloacogenic glandular epithelium and sex-dependent expression in human anal gland. Hum Pathol. 1990;21(11):1108-1111.

6. Mhawech P, Uchida T, Pelte MF. Immunohistochemical profile of high-grade urothelial bladder carcinoma and prostate adenocarcinoma. Hum Pathol. 2002;33(11):1136-1140.

7. Osunkoya AO, Epstein JI. Primary mucin-producing urothelial-type adenocarcinoma of prostate: report of 15 cases. Am J Surg Pathol. 2007;31(9):1323-1329.
8. Liedberg F, Chebil G, Månsson W. Urothelial carcinoma in the prostatic urethra and prostate: current controversies. Expert Rev Anticancer Ther. 2007;7(3):383-390.

9. Palou J, Wood D, Bochner BH, et al; International Consultation on Urologic Disease-European Association of Urology Consultation on Bladder Cancer 2012. ICUD-EAU International Consultation on Bladder Cancer 2012: urothelial carcinoma of the prostate. Eur Urol. 2013;63(1):81-87.

10. Cheville JC, Dundore PA, Bostwick DG, et al. Transitional cell carcinoma of the prostate: clinicopathologic study of 50 cases. Cancer. 1998;82(4):703-707.

11. Ichihara K, Masumori N, Kitamura H, Hasegawa T, Tsukamoto T. Clinical outcomes of urothelial carcinoma of the prostate detected in radical cystectomy specimens. Int J Clin Oncol. 2014;19(1):152-156.

12. Pagano F, Bassi P, Ferrante GL, et al. Is stage pT4a (D1) reliable in assessing transitional cell carcinoma involvement of the prostate in patients with a concurrent bladder cancer? A necessary distinction for contiguous or noncontiguous involvement. J Urol. 1996;155(1): $244-247$.
OncoTargets and Therapy

\section{Publish your work in this journal}

OncoTargets and Therapy is an international, peer-reviewed, open access journal focusing on the pathological basis of all cancers, potential targets for therapy and treatment protocols employed to improve the management of cancer patients. The journal also focuses on the impact of management programs and new therapeutic agents and protocols on

\section{Dovepress}

patient perspectives such as quality of life, adherence and satisfaction. The manuscript management system is completely online and includes a very quick and fair peer-review system, which is all easy to use. Visit http://www.dovepress.com/testimonials.php to read real quotes from published authors. 